\title{
Prolapsed ileocolic intussusception in an adult : A bizarre presentation leading to delayed diagnosis in a low resource setting.
}

\author{
Umar, M., Stephen, Y., Aminu, U., Adogu, I.
}

\begin{abstract}
Background: Intussusception is the telescoping of one part of the intestine into the lumen of the adjoining part, which occurs more in the ileocaecal part of the intestine. It is the most common cause of intestinal obstruction in children younger than 3years of age. Occurrence is rare in adult, with prolapsed intussusceptions even rarer and occuring more in association with an underlying predisposing intestinal abnormality.
\end{abstract}

Case Report: A 19year old boy presented with 6months history of recurrent non-specific, occasionally dull aching abdominal pain, progressive weight loss and a 4hour history of anal protrusion. He had presented multiple times to a peripheral hospital where the definitive diagnosis was missed. He was evaluated for ileocolic intussusception and he had exploratory laparotomy and right hemi colectomy done.

Conclusion: Intussusceptions are rare outside childhood, however there should be a high index of suspicion of intussusception in adult with nonspecific abdominal symptoms who has not responded to conventional conservative therapy.

Keywords: intussusception, ileocolic, tubular adenoma, adult intussusception.

*Corresponding author

Umar, M.

ORCID-NO: http://orcid.org/0000-0003-4792-2136

Email: umarmuktardr@gmail.com

Department of surgery Abubakar Tafawa Balewa University teaching hospital, Bauchi. Nigeria 


\title{
Invagination iléocolique prolapsus dans un adulte: Une présentation bizarre conduisant à un diagnostic retardé dans un contexte de ressources limitées
}

\author{
Umar, M., Stephen, Y., Aminu, U., Adogu, I.
}

\begin{abstract}
Résumé
Contexte général de l'étude : L'intussusception est le télescopage d'une partie de l'intestin dans la lumière de la partie adjacente, qui se produit davantage dans la partie iléo-caecale de l'intestin. C'est la cause la plus fréquente d'obstruction intestinale chez les enfants de moins de 3 ans. La survenue est rare chez l'adulte, avec des intussusceptions prolapsus encore plus rares et se produisant davantage en association avec une anomalie intestinale prédisposante sous-jacente.

Un garçon de 19 ans a présenté des antécédents de 6 mois de douleurs abdominales récurrentes non spécifiques, parfois sourdes, une perte de poids progressive et 4 heures d'antécédents de protrusion anale. Il s'est présenté à plusieurs reprises dans un hôpital périphérique où le diagnostic définitif a été manqué. Il a été évalué pour une invagination iléocolique et il a subi une laparotomie exploratoire et une hémicolectomie droite..
\end{abstract}

Conclusion: Les intussusceptions sont rares en dehors de l'enfance; cependant, il devrait y avoir un indice élevé de suspicion d'intussusception chez l'adulte présentant des symptômes abdominaux non spécifiques qui n'a pas répondu au traitement conservateur conventionnel.

Mots-clés: Intussusception, iléocolique, adénome tubulaire, invagination adulte

*Corresponding author

Umar, M.

ORCID-NO: http://orcid.org/0000-0003-4792-2136

Email: umarmuktardr@gmail.com

Department of surgery Abubakar Tafawa Balewa University teaching hospital, Bauchi. Nigeria

Research Journal of Health Sciences subscribed to terms and conditions of Open Access publication. Articles are distributed under the terms of Creative Commons Licence (CC BY-NC-ND 4.0). (http://creativecommons.org/licences/by-nc-nd/4.0)

http://dx.doi.org/10.4314/rejhs.v9i2.1 


\section{INTRODUCTION}

Intussusception is the telescoping of a proximal gastrointestinal tract into the lumen of an adjacent distal segment and is considered a disease of early childhood occurring more commonly between 4 and 10 months of age (1). It's the main cause of intestinal obstruction in young children predominantly under 5 years of age. In contrast it causes only $1 \%-5 \%$ of adult intestinal obstruction and only $5 \%$ of intussusception is found in adults with 2-3 cases occurring in a population of $1,000,000$ per annum $(2,3)$. Thus a diagnosis of intussusception is not commonly suspected in an adult. While the cause of intussusception is idiopathic in $90 \%$ of children, more than $90 \%$ of cases of adult intussusception is related to an identifiable mechanical lead point such as luminal polyps, benign tumours/masses, malignant tumours, enteric duplication cyst, and Henoch-Schonlein purpura (4-6). A high proportion of the lead points are malignant lesions accounting for $66 \%$ in the colon and $33 \%$ in the small bowel (7).

In the pediatric age group the classical presentation is a triad of colicky abdominal pain, bloody diarrhoea ("currant jelly" stool) and a palpable tender abdominal mass. In adults the presentation varies widely and are nonspecific, most of the cases have been reported as chronic, partial intestinal obstruction making prompt diagnosis a challenge (2-8).

This is a case report of a 19 year old boy who presented with prolapsed ileocolic intussusception predisposed to by a caecal tubular adenoma. The case is reported to highlight this rare occurrence in adulthood as a differential of non specific abdominal pain and thus raise the index of suspicion among clinicians especially those working in low resource setting who do not have the luxury of readily available high definition imaging.

\section{CASE PRESENTATION}

A 19year old boy presented with 6 months history of recurrent non-specific, occasionally dull aching abdominal pain, recurrent non projectile vomiting and progressive weight loss for which he had presented repeatedly to a peripheral hospital.He received hyoscine bromide and analgesics with temporary relieve. Four hours prior to presentation to us the patient developed painful anal protrusion following strain to defecate, the protrusion was irreducible spontaneously nor by patients and his relatives, no previous history of anal protrusion in the past. No previous history of alternating constipation with diarrhoea, no passage of blood or mucus in stool, no fever. On examination, he was acute on chronically ill looking, pale, in moderate painful distress and not dehydrated. The abdomen was flat and moved with respiration without masses were felt on light to deep palpation. There was a prolapsed bowel per rectum with a darkish bluish summit, tender and examining finger was freely insinuated between the mass and the anal verge all round (figure 1A and figure 1B). A tentative diagnosis of prolapsing intussusception was made. An exploratory laparotomy carried out showed a prolapsed ileocolic intussusception which was reduced gradually with a mass was felt at the caecum (lead point). Right hemi colectomy indicated and was carried out (figure 3A and figure 3B). Histological examination showed a section of intestinal segment with tissue oedema and vascular congestion with associated proliferation of tubular glands around fibrovascular stalk but no tissue invasion was seen (figure 2A and figure 2B). Patient recovered uneventfully and was discharged to outpatient for follow up visits. At one year follow up visit, the patient has remained stable and doing well in school.

\section{DISCUSSION}

Intussusception occurs more commonly between 4 and 10 months of age (5), while it is the most common cause of acute intestinal obstruction in infant with a male preponderance of $3: 1$, it is rarely seen in adulthood (8). The classical triad of presentation are a colicky abdominal pain, "currant jelly" stool/dysentery and a palpable mass in the abdomen/vomiting seen commonly in infants and children (8). This triad is not well defined in adulthood which is partly responsible for delay in diagnosing the case being reported (9). Adults generally presents with nonspecific long standing abdominal symptoms and the classic triad is rarely seen (10). Vomiting and bleeding from the rectum are the other common symptoms in adult (6). The pain as seen in children is often periodic in nature.

The ileocolic portion of the intestine is usually involved among children (10). Intussusception is idiopathic in $90 \%$ of children (4), in contrast more than $90 \%$ of adult intussusception are related to a mechanical cause with a mechanical lead point for intussusception which may be luminal polyps (both adenomatous and non-adenomatous), benign tumours/masses, malignant tumours, enteric duplication cyst, Henoch-Schonlein purpura $(5,8)$. Our patient had 
a tubular adenoma of the colon, a known precancerous lesion which was the mechanical lead point for the development of the intussusception in the patient.

When the intussusception invaginates and pulls along the mesentery, there is compromise of venous return. This is followed by engorgement of the intussuceptum, oedema and bleeding from mucosa which lead to currant jelly stools. Finally the arterial blood supply of the intestine gets compromised leading to necrosis, perforation and shock (11). In the index case the intussuscepiens was able to navigate the colon to prolapse through the anal canal without necrosis, perforation nor shock. This is a very rare complication of intussusception seen in long standing intussusceptions where diagnosis have been delayed in patients with background mobile right side colon due to non fixity of caecum and ascending colon (12-14).

With low index of suspicion for intussusception, these patients often get symptomatic treatment (as seen in our patient who was managed symptomatically for 6 months) and are often labelled as having irritable bowel disease (12). Intussusceptions can most often be diagnosed with contrast enhanced computer tomography (1), The diagnosis is more often missed or delayed in low resource settings because of low index of suspicion, patients are often not referred to do this hardly-available and expensive procedure such as was exemplified in case under discussion.

Prolapsed intussusception as a result of delayed management of intussusception can be differentiated from rectal prolapse by careful examination. In rectal prolapse continuity can be palpated between the perianal/anal tissue and the protruding tissue, whereas in intussusception there is no palpable continuity and the finger can be freely passed between the anorectal wall and the prolapse through the circumference as seen in the patient being reported (10).

In cases of intussusception in children, resection can be avoided if the intestine is viable, most managed conservatively, as over $90 \%$ are idiopathic without an identifiable lead point. However in adults Azar et al suggested that surgical resection is preferred as almost $50 \%$ of both colonic and enteric intussusception are associated with malignancy as the lead point (2). However with recent evidence it has been recommended that resectional surgery for adult intussusceptions should be selectively based on location and underlying pathology (15). For those above 60years with a colonic pathology where malignancy and precancerous lesions are highly likely resection should be done while for patients with small bowel lesions or known benign underlying diseases (such as tropical sprue, Crohns) where malignancy is not highly likely and a small bowel syndrome will most likely result, a non-resectional surgery is advocated if the bowels are viable (15). The patient reported had reduction of the prolapsed segment and right hemicolectomy and histology of the resected segment showed tubular adenoma of the caecum. The resection in this patient was informed by the caecal position of the lead point which turned out to be a precancerous lesion.

\section{CONCLUSION}

Intussusception is predominantly a disease of childhood only rarely seen in adults where it often has bizarre presentation which lead to misdiagnosis and delayed treatment and thus unpleasant outcomes. High index of suspicion is necessary in any adult with recurrent, unspecific abdominal symptoms which persist despite medical management in other to prevent such unpleasant complication.

Learning points/take home messages:

- Intussusception though rare in adults is a possible cause of abdominal symptoms in adults

- Presentation in adults unlike childhood is non-specific

- There is thus a need for high index of suspicion for adults' patients presenting with non-specific abdominal symptoms

- Clinicians working in low resource settings should have a low threshold for referral of these group of patients to centers where appropriate imaging can be done and diagnosis made to avoid unpleasant complications.

Conflicts of interest: Authors declares no conflicts of interest.

\section{REFERENCES}

1. Gayer G, Apter S, Hofmann C, Nass S, Amitai M, Zissin R, et al. Intussusception in adults: CT diagnosis. Clin Radiol. 1998 Jan;53(1):53-7.

2. Azar T, Berger DL. Adult intussusception. Ann Surg. 1997 Aug;226(2):134-8.

3. Lu T, Chng Y. Adult intussusception. Perm J. 2015;19(1):79-81.

4. Marinis A, Yiallourou A, Samanides L, Dafnios N, Anastasopoulos G, Vassiliou I, et al. Intussusception of the bowel in adults: a review. World J Gastroenterol. 2009 Jan 28;15(4):407-11. 
5. Hackam DJ, Grikscheit TC, Wang KS, Newman KD, Ford HR. Chapter 39. Pediatric Surgery. In: Brunicardi FC, Andersen DK, Billiar TR, Dunn DL, Hunter JG, Matthews JB, et al., editors. Schwartz's Principles of Surgery [Internet]. 9th ed. New York, NY: The McGraw-Hill Companies; 2010 [cited 2019 Nov 12]. Available from: accesssurgery.mhmedical.com/content.aspx?aid= 5029784

6. Lianos G, Xeropotamos N, Bali C, Baltoggiannis $\mathrm{G}$, Ignatiadou E. Adult bowel intussusception: presentation, location, etiology, diagnosis and treatment. G Chir. 2013 Oct;34(9-10):280-3.

7. Barussaud M, Regenet N, Briennon X, de Kerviler B, Pessaux P, Kohneh-Sharhi N, et al. Clinical spectrum and surgical approach of adult intussusceptions: a multicentric study. Int J Colorectal Dis. 2006 Dec 1;21(8):834-9.

8. Jain S, Haydel MJ. Child Intussusception. In: StatPearls [Internet]. Treasure Island (FL): StatPearls Publishing; 2020 [cited 2021 Feb 20]. A v a i 1 a b l e f r o m : http://www.ncbi.nlm.nih.gov/books/NBK431078 /

9. Rathore MA, Andrabi SIH, Mansha M. Adult intussusception--a surgical dilemma. J Ayub Med
Coll Abbottabad. 2006 Sep;18(3):3-6.

10. Yalamarthi S, Smith RC. Adult intussusception: case reports and review of literature. Postgrad Med J. 2005 Mar;81(953):174-7.

11. Pineda C, Hardasmalani M. Pediatric intussusception: A Case Series and Literature Review. The Internet Journal of Pediatrics and Neonatology [Internet]. 2008 Dec 31 [cited 2019 Nov 12];11(1). Available from: http://ispub.com/IJPN/11/1/11337

12. Ngom G, Fall I, Sankale AA, Konate I, Sagna A, Ndoye M. Prolapsed intussusception in children: A report of 4 cases. African Journal of Paediatric Surgery. 2005 Feb 1;2(1): 17.

13. Frydman J, Ben-Ishay O, Kluger Y. Total ileocolic intussusception with rectal prolapse presenting in an adult: a case report and review of the literature. World J Emerg Surg. 2013 Sep 23;8:37.

14. Ibrahim IA. Prolapsed ileocolic intussusception. Annals of Pediatric Surgery. 2011 Apr;7(2):76-8.

15. Olasky J, Moazzez A, Barrera K, Clarke T, Shriki J, Sohn HJ, et al. In the era of routine use of CT scan for acute abdominal pain, should all adults with small bowel intussusception undergo surgery? Am Surg. 2009 Oct;75(10):958-61

How to cite this article:

Umar, M., Stephen, Y., Aminu, U., Adogu, I. Prolapsed ileocolic intussusception in an adult: A bizarre presentation leading to delayed diagnosis in a low resource setting. Research Journal of Health Sciences, 2021, 9(2): 115-120 


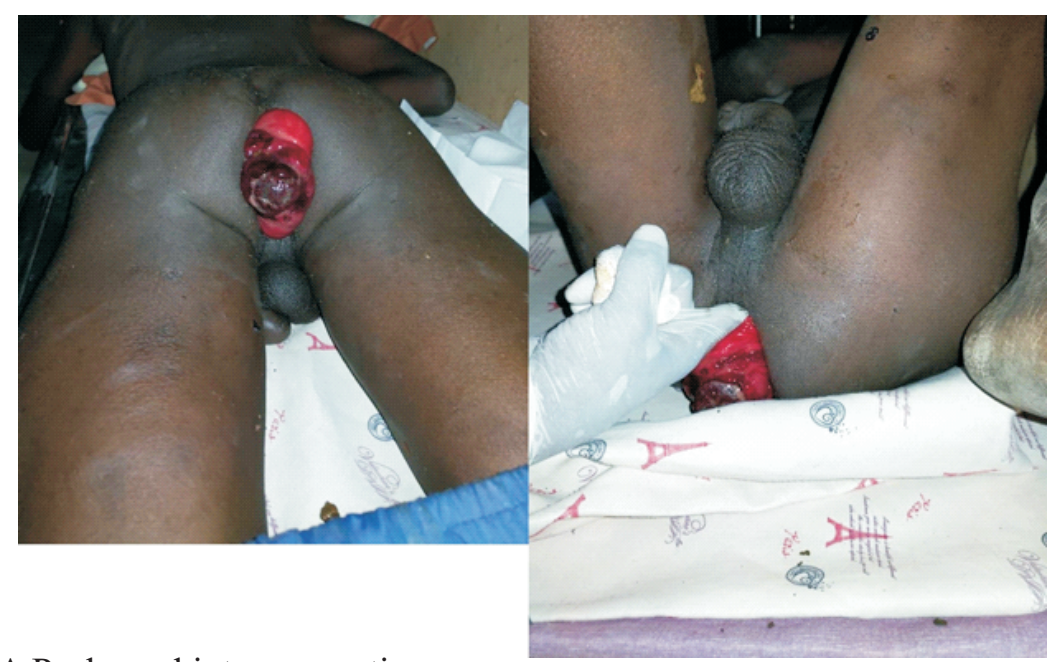

Figure 1A Prolapsed intussusception

Figure 1B Demonstrating insinuation of finger between intussuscipien and the rectal wall

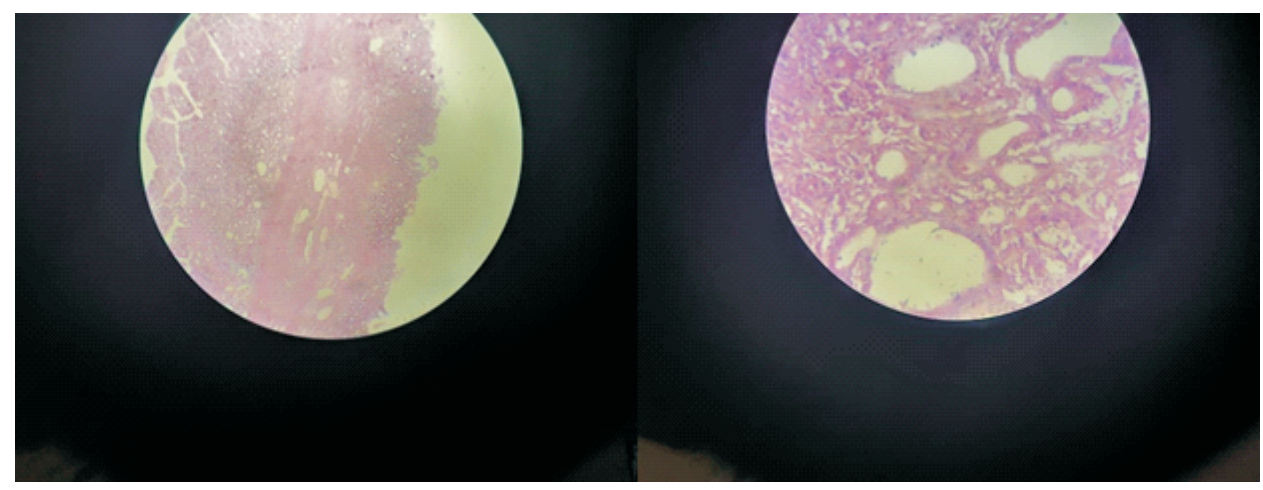

Figure 2A Moderately dysplastic tubular adenoma around fibrovascular stalk with no evidence of invasion of the stalk X10

Figure 2B Dysplastic tubules X20

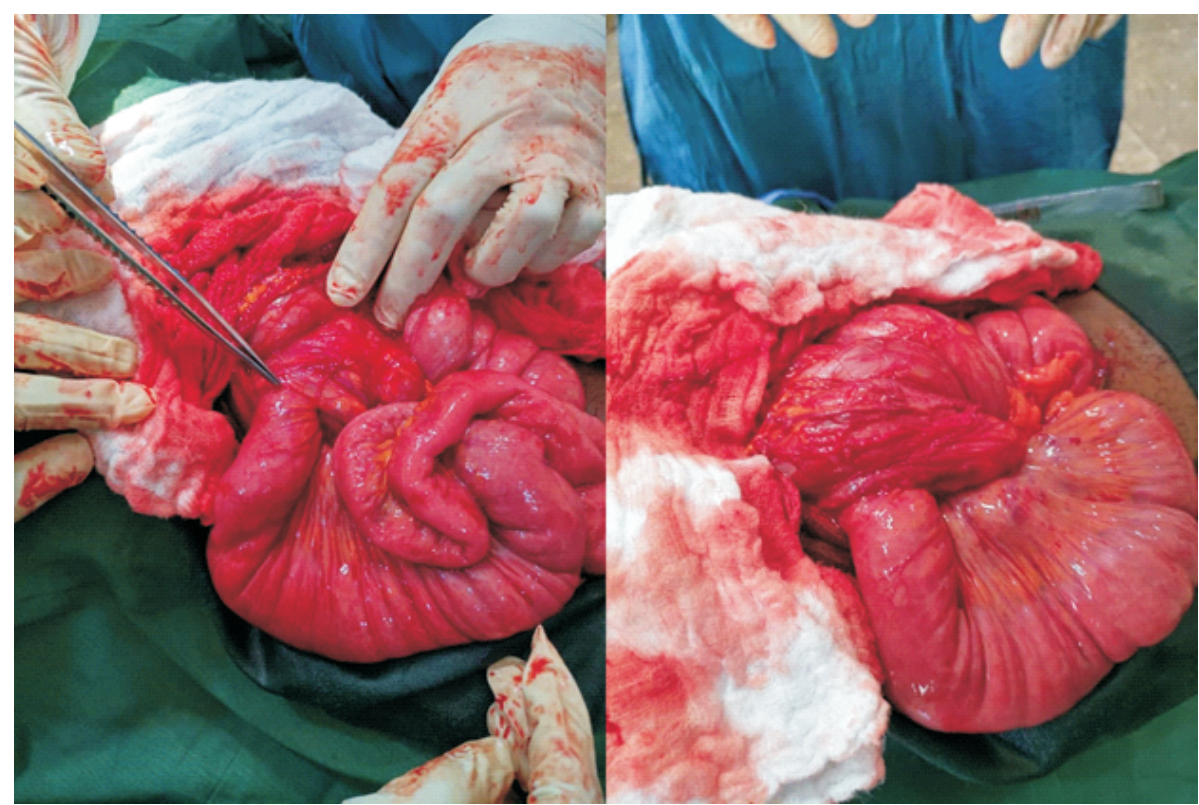

Figure 3A Proximal point of the telescoping small bowel

Figure 3B Intra-operative picture of the intussusception 